\title{
A Balanced Scorecard for Managing the Aging Workforce
}

\author{
SVEN C. VOELPEL CHRISTOPH K. STREB
}

\section{INTRODUCTION}

In most industrialized countries, organizational science and practical management have fully accepted the challenge of dealing with the aging of the available labor pool. The demographic data on companies' workforces have made it clear that the average age within their organizations is continuously increasing. Simultaneously, they find it more difficult to attract capable and younger replacements, whether for blue or white collar positions across all industries.

The average age is not, as such, a cause for company concern. The related challenges and problems that could arise in the long term do, however, need to be taken seriously. Empirical studies have proven that, first, there is a tendency towards a growing number of constrained workers and employees who are less flexible in terms of their employment if a company's personnel are of a higher average age. Second, such a workforce's number of sick days (but not the number of illnesses) increases due to their requiring a longer convalescent period. Third, employees who retire could be taking important knowledge with themespecially if the timely transfer of knowledge to the next generation (if available) has been ignored.

The detailed issues and challenges arising from an aging workforce are very specific, depending largely on the business environment, the industry, and the organizational culture. However, these issues and challenges' potential effects on organizations' overall strategic performance, especially in terms of cost structure and, thus, financial performance, are obvious. An organization that has to be managed while many of its employees are on extended sick leave or finds that important key employees have taken their unique know-how with them when retiring will struggle in a competitive business environment.

Facing and acknowledging the above problems, eight global corporations headquartered in Germany and Switzerland (Daimler AG, Deutsche Bahn AG, Deutsche Bank AG, EnBW AG, Lonza Inc., Mars Inc., Otto Group, and Volkswagen AG) formed a joint network. This network is aimed at addressing and mastering the mutual challenges arising from the aging workforce and developing appropriate strategic tools with which these organizations can maintain their performance. All the participating companies recognize that there is an ongoing and active debate with regard to their demographic situation. Moreover, they realize that a systematic and concerted effort should be made to develop strategies as a tool to protect their demographic fitness and to improve their competitive and innovative abilities on the long term.

In the words of Martina Klug of EnBW AG: "Participating in the network enabled us to deduce pragmatic approaches based on science and to share experiences with other companies that also have to deal with this issue." Michael Adolf Picard, personnel director at the Otto Group, agrees: "In our opinion, it is critical that the demographic change is taken seriously and that we act at an early stage. On the other hand, it is important to avoid wild actionism (acting for the sake of acting) and panic. In my opinion, the recent demographic development is not a revolution but an evolution, which allows a targeted reaction." Carla Berg, Mars University's talent manager, states: "The better we prepare ourselves at an early stage, the more successful we will be in the future."

It is therefore clear that a model is required with which an aging workforce's performance in respect of organizational competitiveness and innovativeness can be measured, monitored and adjusted by paying specific attention to productivity and creativity measures. Based on the insights gained from the data collected in the relevant companies' numerous moderated joint sessions, this article will introduce such a model.

However, we start off by first introducing our data collection approach via a needs assessment and analysis of the participating companies; thereafter, we discuss the five organizational action fields that are relevant to the issue, and ultimately introduce a balanced scorecard for managing the aging workforce.

\section{NEEDS ASSESSMENT AND ANALYSIS AS AN EMPIRICAL SOURCE}

We employed a unique empirical approach in our data collecting and results testing in order to develop a scorecard that will allow organizations to measure their performance and identify critical issues regarding the aging workforce. In close cooperation with representatives of the personnel departments of Daim- 
ler, Deutsche Bahn, Deutsche Bank, EnBW, Lonza, Mars, Otto, and Volkswagen, we developed a guideline for identifying, structuring, and documenting information and problems related to the demographic development.

Through moderated workshops and qualitative individual interviews, we compiled the data required to document the demographic status quo in production, research and development, personnel, and sales and marketing. The aim was to identify and pool common needs for action. According to Matthias Afting, head of personnel and education strategy at Deutsche Bahn: "Since we employ about 190,000 people in Germany, it is firstly important for us to thoroughly analyse the demographic situation of our company in order to initiate measures, for example, for early recruitment and proactive qualification."

The challenge that we faced regarding mobilizing participants from all departments was more than compensated for by the workshops' positive results: besides obtaining recent and complete demographic data, we also engendered awareness of the demographic situation within the company and the topic's overall importance. "When talking about the so-called older employees as a critical target group, some discussants realized for the first time they were actually talking about themselves," stated Michael Adolf Picard of the Otto Group.

Openly discussing company-specific perceptual images and prejudice concerning "age" and the "aging workforce" led to surprising insights. These discussions also sensitized the participants to the ongoing, mostly negative, perceptual and evaluative patterns applied to older employees' performance, development, and learning capacities. "If aging employees are ignored and feel that they are largely superfluous, this attitude arises over time," remarked Alfred Zimmerli of Lonza.

Despite the organizers and initiators' initial concerns, the workshops proved to be a suitable forum for openly discussing sensitive topics without loss of face. According to one company representative: "It is an exciting and complex yet pressing topic. The central question was not 'who failed to do what?' but 'how do we manage to meet the challenges?"'

The needs assessment workshops elaborated on the relevant fields of activity for the specific company divisions and asked how consistent or - depending on the division - specific was the need for action. An overview of the workshops' results indicated that all the companies acknowledged a general need for action, although the individual companies' needs differed with regard to their focal points. On the one hand, all the companies mentioned human resources management as the most important field of action, since this comprises the recruiting, retention and retirement of specialists and executives. Other focal issues were: demography-related career monitoring, planning, and coaching; succession plans; human resources development; working hours; transitional arrangements at the end of a career; and the recruitment and promotion of young employees.

On the other hand, knowledge management was identified as almost equally important. In this respect, companies' focus is mainly on the handling of critical knowledge. The demographic change and related questions concerning the documentation and transfer of critical knowledge and know-how have made managing this type of knowledge more problematic.

With regard to identifying more specific fields of action, various industrial sectors had differing focal points. Production companies (or divisions) with a large percentage of commercial and blue collar workers emphasize human resources management and the arrangement of the working environment. Conversely, companies that are very dependent on innovation emphasize knowledge management. Finally, for service industry companies, their employees' behavior and attitude are the predominant consideration.

Although the number of participating companies was rather small, we were able to identify typical "need patterns." These patterns were then classified into measures within specific fields of action that need to be implemented:

- "Homogeneous needs:" These are needs that are consistent across departments. In most cases, there was a strong need for the implementation of human resources management measures.

- "Heterogeneous needs:" In some companies there was a need for action in all the fields.

- "Need focus:" This refers to need patterns whose characteristics are depending on whether they are located in companies' central or peripheral parts. For example, in one company, the knowledge management and behavior/attitude of its employees were exceptionally critical in its central departments, whereas human resources management and the working environment were especially important in its peripheral departments.

- "Temporary needs:" These can be found in companies with a concrete but short-term need of measures from different fields of action. Temporary needs can include, for example, knowledge management in the sales and marketing department in times of new market entry, or human resources management in the information technology (IT) department in times of labor shortage.

On the whole, the workshops experiences and the results of the analyses support the investment of time and effort to explicitly analyse all of a company's departments. It is critical to obtain information that provides a realistic depiction of the organization's different starting points and needs. Simultaneously, the analyses became a dilemma for the participating 
companies: the more detailed the analysis, the more information was generated, and the more diverse and inconsistent the identified needs for action were. It is therefore essential that an appropriate balance be found between analysis and implementation.

\section{THE FIVE ACTION FIELDS}

Most companies, irrespective of their industrial sector, agree on the importance of the following key measures when they aim to improve or maintain their competitiveness and innovativeness: productivity and creativity. Productivity can generally be defined as the mechanism and measure of efficiency, i.e., realizing a greater output with the same input, or the same output with less input. Creativity is regarded as human ingenuity, which is key to organizational innovativeness with respect to business models, strategies, markets, products, services, and processes.

Science is still controversially discussing whether there is indeed a correlation between age and a potential decline in productivity and creativity. To date, no confirmation or repudiation has been identified in this respect on the individual, group, and organizational level. Nevertheless, it seems that the managerial mindset tends to regard age as a potential negative impact factor. Managers are increasingly wondering whether the aging of their available workforce is a serious threat to their organization's overall competitiveness and innovativeness. Furthermore, if this were to be true, how do they avoid the potential downsides of an older staff on average, and leverage their specific strengths, like their experience?

Our research was aimed at providing important insights so that these questions can be answered. It first of all allowed us to deduce a framework of five crucial organizational action fields on which managers need to focus to increase their employees' productivity and creativity (see Fig. 1). This framework is one of the key findings of our needs assessment and analysis, providing the focus required to develop a balanced scorecard to measure and monitor the aging workforce's overall performance.

A few important characteristics of the illustrated framework and its components, which underlie the scorecard, need to be highlighted:

- A critical prerequisite is a new managerial mindset towards the older workers. Not only should individual capabilities be appreciated and trust be fostered between the management and the workforce, but the necessary processes and tools should also be implemented.

- Knowledge management processes depend on effective human resource management processes. This includes supporting knowledge management by nurturing an appropriate attitude in the older workforce; by

\section{Figure 1 Organizational Action Fields to Manage the Aging Workforce}

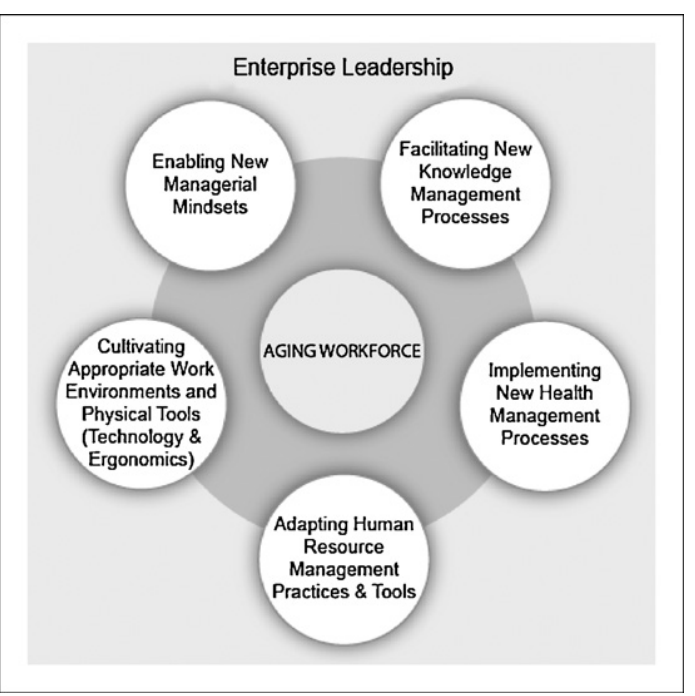

taking their physical capabilities into consideration; and by providing appropriate work environments, organizational culture, leadership, and applied (physical) tools.

- Health management is another critical component of successfully managing an aging workforce. It is closely linked to issues such as a new mindset, workers' physical performance, work security, ergonomics, and related knowledge and human resource practices. Moreover, health is not just a question of physical well-being, but also includes mental and emotional aspects, especially with regards to stress-related psychosomatic illnesses.

- Current human resources management practices and tools need to be adapted in the light of the aging of the workforce. In our knowledge and innovation economy, revised human resource management functions need to incorporate issues that go beyond the obvious ones, such as talent management (recruiting, retention, and retirement), to include those from all four of the organizational action fields. Again, this also requires a shift in the responsible leaders' mindset.

- An appropriate work environment as well as ergonomic measures is key. This does not only apply to organizations that rely on physical labor, but also to any company that wants to maximize the implementation of measures related to the other action fields.

- The proposed framework does not follow a mechanical paradigm, but relies on a step-by-step response and application. It is a dynamic concept with interrelated and interdependent elements and 
components that need to be viewed and addressed holistically. If one element is neglected, this jeopardizes the entire approach. However, it cannot be denied that human resource issues do predominate somewhat.

- Both the top management and functional leaders are responsible for preparing, implementing, and monitoring the related measures in order to sustain and improve their company's competitiveness and innovativeness.

It should be noted, however, that there may be many reasons for productivity increasing. Not only is it important to do things right, but the right things should also be done. Processes, products, and services can only be improved if all factors, such as knowledge management and human resource management, are aligned, and cross-fertilization occurs. The appropriate tools are critical. Moreover, creativity and, thus, innovativeness can be increased when mindsets engage in improved or completely new ways of thinking and of approaching problems. Innovativeness, for example, depends on appropriate knowledge management practices and work environments, but also requires healthy employees who are mentally, physically and emotionally committed. This requires the above-mentioned action fields to be considered and monitored holistically.

\section{THE BALANCED SCORECARD FOR AGING WORKFORCE MANAGEMENT}

The brief descriptions of the key action fields in organizational aging workforce management as identified in our research raise one very important question: how can improvements and progress within these action fields be measured? This question needs to be answered if an affected company is to be successfully guided towards productivity and creativity, which directly address its competitiveness and innovativeness. Naturally, each field requires specific strategies, measures, and tools aimed at maintaining a certain performance level. These are unique and dependent on the organization's particular situation and business. However, responsible management and leadership are ultimately needed to define the goals and thereafter monitor and assess whether they have been met.

Owing to the individuality of each enterprise and industry, and thus, the challenges they face as a result of the aging workforce, it is beyond the scope of this article to propose detailed measurements of each conceivable field that would be appropriate for all of them. However, as illustrated in Fig. 2, our proposed balanced scorecard can facilitate the assessment and monitoring processes.

\section{Figure 2 The Balanced Scorecard for Aging Workforce Management}

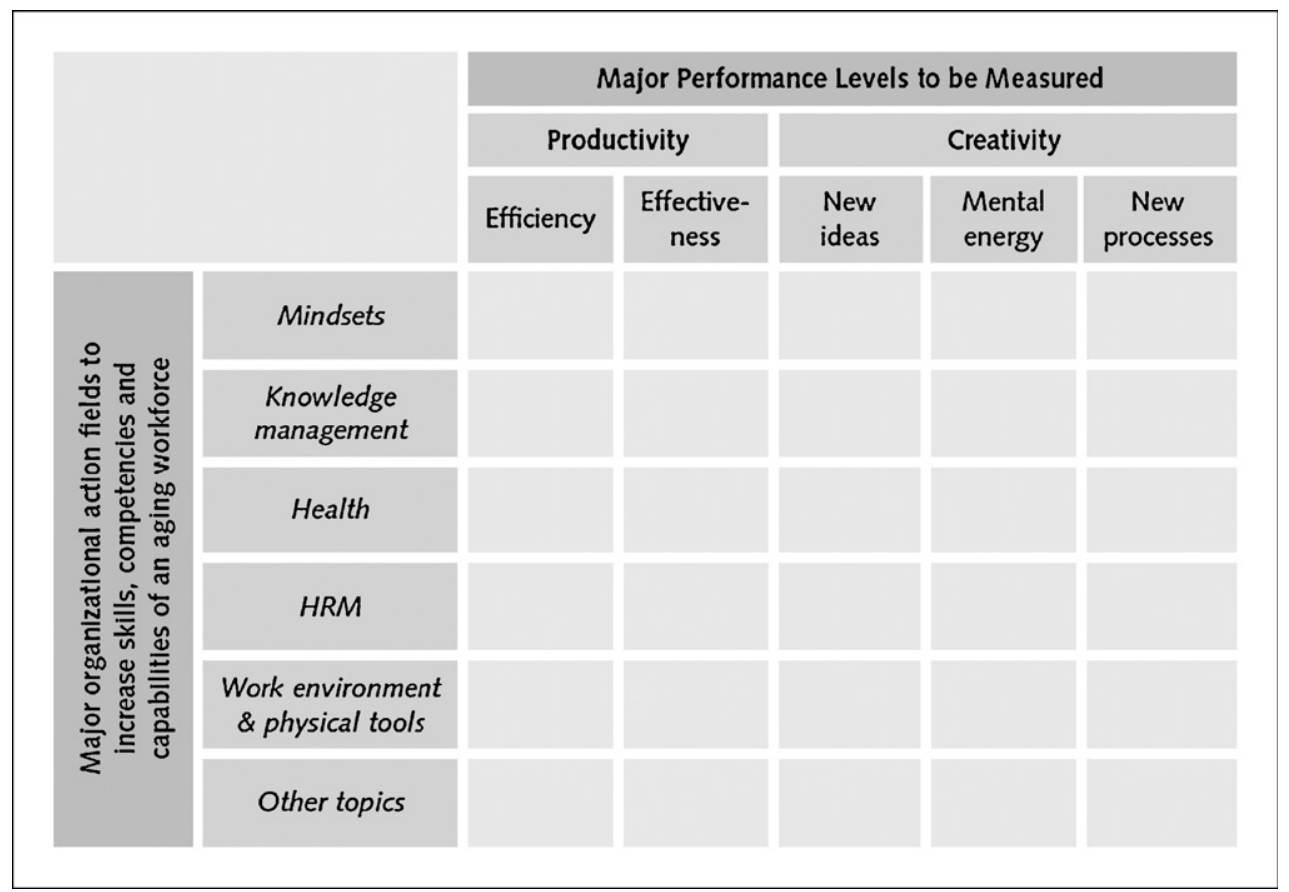


This scorecard is largely based on the action field framework introduced above. Most important, it incorporates the dynamic and systemic interrelatedness of the identified action fields. All five action fields are represented on this balanced scorecard, which offers the possibility to extend the table by adding more fields on the left. At the top of the table appear the two major performance levels to be measured: productivity and creativity.

Productivity as a measure of organizational success is well developed. Numerous key figures, which generally give an indication of the efficiency and effectiveness of measures taken, are at the organization's disposal. Quantifying creativity is, however, more difficult. Ideally, the creativity level can be measured by, for example, an organization's number of innovations, their quality (in terms of market success or revenue generated), and perhaps by the effective use of the resources required as an investment to produce a new innovation. Nonetheless, mental levels of creativity, especially on the individual level, are difficult to research in theory and even more difficult to measure in practice. Once again the scorecard's success depends on the ingenuity of the leaders behind the process and how they undertake to operationalize their organization's productivity and, especially, its creativity.

In general, there are numerous types of quantitative and qualitative measures: auditing, surveying, interviewing, and psychometric testing techniques. All of these can either be more quantitative or more qualitative. By successfully analysing, monitoring, and steering their proposed action fields and measures companies can develop an individual balanced scorecard. With this, they can navigate the organization towards competitiveness and innovativeness despite the potential downsides of an aging workforce. Moreover, the proposed approach can either be applied to the organization as a whole, or to various functional levels to further verify the success of the applied measurements and whether the resulting key figures reflect these.The actual application of the demographic scorecard may be problematic at first. Consequently, Fig. 3 provides an example of how other enterprises apply this specific tool.

\section{Figure 3 Examples of the Scorecard Application}

\begin{tabular}{|c|c|c|c|c|}
\hline Action field & Objective & $\begin{array}{l}\text { Implementation } \\
\text { tool }\end{array}$ & $\begin{array}{l}\text { Measurement } \\
\text { tool }\end{array}$ & $\begin{array}{l}\text { Corporate } \\
\text { example }\end{array}$ \\
\hline $\begin{array}{l}\text { Mindset } \\
\text { Change }\end{array}$ & $\begin{array}{l}\text { Positive attitude } \\
\text { towards } \\
\text { innovation }\end{array}$ & e-Learning & $\begin{array}{l}\text { Rating survey } \\
\text { of attitudes }\end{array}$ & Lufthansa \\
\hline $\begin{array}{l}\text { Knowledge } \\
\text { Management }\end{array}$ & $\begin{array}{l}\text { Retention } \\
\text { of valuable } \\
\text { know-how }\end{array}$ & $\begin{array}{l}\text { Knowledge- } \\
\text { depositories }\end{array}$ & $\begin{array}{l}\text { Knowledge } \\
\text { audits }\end{array}$ & Volkswagen \\
\hline $\begin{array}{l}\text { Health \& } \\
\text { Ergonomics }\end{array}$ & $\begin{array}{l}\text { Physical } \\
\text { performance } \\
\text { improvements }\end{array}$ & $\begin{array}{l}\text { Workplace } \\
\text { reorganization }\end{array}$ & $\begin{array}{l}\text { Workability } \\
\text { index; obser- } \\
\text { vations }\end{array}$ & $\begin{array}{l}\text { Daimler- } \\
\text { Chrysler }\end{array}$ \\
\hline$H R M(1)$ & $\begin{array}{l}\text { Increase in } \\
\text { work flexibility } \\
\text { and sharing }\end{array}$ & $\begin{array}{l}\text { People } \\
\text { Sharenet }\end{array}$ & $\begin{array}{l}\text { Job satisfaction } \\
\text { survey \& ratings; } \\
\text { trust ratings }\end{array}$ & Siemens \\
\hline$H R M(2)$ & Job matching & $\begin{array}{l}\text { Software-linked } \\
\text { trade-offs }\end{array}$ & $\begin{array}{l}\text { Job turnover; } \\
\text { job loyalty }\end{array}$ & BMW \\
\hline
\end{tabular}




\section{CONCLUSION}

The five action fields framework and the balanced scorecard for managing an aging workforce towards competitiveness and innovativeness introduced in this article are the result of a unique and rich data-collecting approach. Via a needs assessment and subsequent needs analysis, the most important issues that diverse companies face in respect to the challenges of an aging labor pool are identified. By focusing, categorizing, and realigning individual company concerns as well as providing solutions to the question how organizations can successfully manage the aging workforce, we could deduce a scorecard. This scorecard not only allows managers to identify, specify, and focus their efforts with regard to the aging workforce challenge, but also to monitor and adjust their actions.

Our scorecard can therefore be compared to the well-known strategic balanced scorecard by Kaplan and Norton. It also serves as a controlling, steering, and communication tool. Through the continuous querying of key financial performance figures, both quantitatively and qualitatively, our scorecard allows constant monitoring of the current status quo and a course correction if the company deviates from its defined strategic goals. The conventional strategic balanced scorecard is more general and is commonly structured to reflect financial, customer, internal business processes, learning, and growth perspectives. Conversely, the balanced scorecard that we present here focuses strictly on the action fields that are relevant for the organization in terms of aging workforce management. The proposed action fields and measures described in this article are by no means exhaustive. We thus strongly suggest that practitioners adapt the scorecard to meet their individual needs. The dynamics behind the interrelated elements should, however, not be neglected.

Since the findings that led to the proposed scorecard are limited due to the limited sample and the scope of the field as far as the participating companies are concerned, we strongly encourage critical studies. Not only should such studies investigate the generalizability of action fields, but should also specifically investigate the successful application of the scorecard in practice.

To order reprints of this article, please call $+1(212) 633-3813$ or e-mail reprints@elsevier.com 


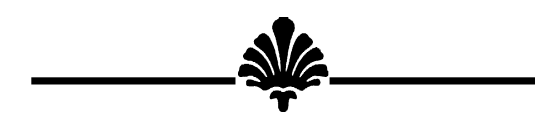

\section{SELECTED BIBLIOGRAPHY}

For more details on aging workforce management, see M. Leibold and S. Voelpel, Managing the Aging Workforce: Challenges and Solutions (New York, NY: Wiley, 2006). For further issues regarding the specific requirements of the knowledge and innovation economy as referred to in this article, we suggest $\mathrm{T}$. $\mathrm{H}$. Davenport, M. Leibold, and S. Voelpel, Strategic Management in the Innovation Economy (New York, NY: Wiley, 2006). Detailed research published with respect to the aging related studies mentioned in this article can be found at, for example, C. Streb, S. Voelpel, and

\begin{abstract}
M. Leibold, "Managing the Aging Workforce: Status Quo and Implications for the Advancement of Theory and Practice," European Management Journal, 2008, 26 , 1-10 or C. Streb and S. Voelpel, "Analyzing the Effectiveness of Contemporary Aging Workforce Management-The Case of Daimler AG," Organizational Dynamics (in press). For a detailed overview of the balanced scorecard, the reader can refer to, for example, R. S. Kaplan and D. P. Norton, Balanced Scorecard: Translating Strategy into Action (New York, NY: McGraw-Hill, 1996).
\end{abstract}

Sven C. Voelpel is founder and director of the WISE Demographic Network and the WISE Research Group and professor of business administration at the Jacobs Center on Lifelong Learning and Institutional Development at the Jacobs University Bremen. His research explores the fields of Wisdom, Innovation, Strategy and Energy (WISE). He has contributed to these domains with more than 100 publications in books and journals, including the Academy of Management Journal. His most recent books are "Managing the Aging Workforce" (with Marius Leibold) and "Strategic Management in the Innovation Economy" (with Thomas Davenport and Marius Leibold). He has held and holds various (honorary) professorships at the leading universities and business schools on four continents as well as visiting fellowships at Harvard University (Jacobs Center on Lifelong Learning, Jacobs University Bremen, Campus Ring 1, 28759 Bremen, Germany; e-mail: s.voelpel@jacobs-university.de).

Christoph K. Streb is an assistant professor and SOM Research Institute Fellow at the department of innovation management and strategy at the University of Groningen. He received his Ph.D. after his research on the constituting elements of aging workforce management in the automobile industry. His current research evolves around related issues, specifically considering the implications of the aging workforce for small business management and entrepreneurship. He is the author of several well-cited publications on the topic of aging workforce management and serves on the advisory board of distinguished companies, offering consultation in related matters (Faculty of Economics and Business, University of Groningen, Nettelbosje 2 (WSN 416), 9747 AD Groningen, The Netherlands; e-mail: c.k.streb@rug.nl). 